\title{
Further Notes on the Ngaloba Industry, a Middle Stone Age Assemblage Directly Associated with Early Homo in the Greater Laetoli, Northern Tanzania
}

\author{
Fidelis T. Masao and Jackson S. Kimambo
}

Laetoli is a well-known palaeontological locality in northern Tanzania whose outstanding record includes not only the earliest hominid footprints in the world, but also offers evidence of human cultural and biological evolution. The hominid footprint, discovered by the late Mary Leakey in the 197os, subsequent to a recent discovery by one of the authors, is unique and the oldest evidence for early human bipedal locomotion dating to 3.6 Mya (Masao et al., 2016; Leakey, 1984, 1987a, 1987b, 1987c; Leakey and Hay, 1979; Leakey et al., 1978; Drake and Curtis, 1987). In addition to the hominin and animal footprints, the area has yielded several hominid fossil remains and stone tools (Harrison, 2011, 2002, 1997, 1981; Harris, 1985; Magori and Day, 1983; Su and White, 2015; White, 1980). The archeological significance of the Laetoli area was first recorded in 1938-39 by Kohl Larsen, who collected and reported bifacial implements and hominin fossil remains (Kohl-Larsen, 1943). In 1935, Louis and Marry Leakey visited Laetoli and collected some fossil vertebrates and terrestrial gastropods, which were sent to and housed at the Natural History Museum in London (Leakey, 1987a; Harrison, 2011; Leakey and Harris, 1987). The Leakeys being occupied with research at Olduvai, could not subject the area to the intensive investigation until 1974 when Mary Leakey was able to turn her attention to the area (Leakey, 1984, 1979, 1978).

Mary Leakey's 1974-75 field season was aimed at collecting fossil remains and to intensively search for stone tools (Leakey and Harris, 1987; Clarke, 1978). Given her knowledge of archeostratigraphy, she was of the opinion that because the Laetoli beds were older than Olduvai, the area might harbor stone tools predating the Early Stone Age deposit at Olduvai (Leakey and Harris, 1987; Harrison, 2011). Consequently, the Laetoli beds were investigated by Harris and Leakey (Harris, 1979), but they found no traces of tools or foreign materials 
predating the Oldowan. Instead, an abundance of scatters of artefacts associated with the Ngaloba beds was reported to exist in most of the site (Hay, 1987). Unfortunately, the reported stone tools assemblages were not fully studied.

In 1990, Ndesokia studied the archaeological composition of Olpiro and Ngaloba beds at Locality 16. Ndesokia's (1990) findings revealed lithic artefacts that were described as Developed Oldowan and Acheulean. In comparison with the assemblages from Olduvai, the aggregates from Olpiro beds were thought to be comparable to the Acheulean aggregates from the Olduvai sites of MNK, SHK, and FC west (Ndesokia, 1990). Despite the fact that the upper Ngaloba beds correspond with the MSA period, his study did not document Middle Stone Age (MSA) from the area. Though scattered artefacts from the surface were reported, their classification and categorization went unnoticed.

It was not until 2002 when Adelsberger and Mabulla briefly studied the provenience of MSA tools in Laetoli, and in 2011, the same authors analysed the geochemical and mineralogical attributes of these stone tools in order to identify a possible source of the raw materials (Adelsberger et al., 2002; 2011). The study stated that only materials identified as MSA were used for analysis, and materials suspected to be LSA were not included in their analysis. Results generated from Adelsberger et al., 2002; 2011 provide insightful information about the sourcing of raw material used for stone tool making at Laetoli. However, spatial distribution and occurrence of human activities during the MSA period at Greater Laetoli including the nearby Kakesio area has not been studied. Therefore, a short fieldwork was initiated in 2018 to document the distribution of archaeological remains, mostly MSA, across the Ngaloba beds landscape. The goal of this field trip was an effort to document the occurrences of the MSA for a better understanding of the cultural expression of Early Homo sapiens (EHs), stratigraphically associated with the Ngaloba MSA assemblages.

The MSA in Africa which is also described as the Middle Palaeolithic in Europe and the Middle East dates between 20okya and 3okya (Willoughby, 2006; d'Ericco and Banks, 2013). New dating techniques and more accurate climate correlations have placed the MSA beyond rooka (Henshilwood et al., 2013; d' Errico et al., 2009; Marean et al., 2007), and now considered contemporaneous with Eurasia Middle Palaeolithic. Early MSA technologies could have been in place by ca $285 \mathrm{ka}$ and lasted until Ca. $40-30 \mathrm{ka}$ (Henshilwood et al., 2013). 
This Middle Pleistocene period represents the beginning of regional variation in technological and cultural adaptation as well as the period when modern humans appeared (Willoughby, 20o6). During this time, Europe was occupied by Homo neanderthalensis (d'Ericco and Banks, 2013). In Africa, the MSA is associated with both anatomically modern man (Homo sapiens) as well as Archaic Homo sapiens (Rightmire, 2009). Early physical evidence comes from the Gademotta Formation in Ethiopia, the Kapthurian Formation in Kenya, and Kathu Pan in South Africa (Herries, 2011).

Other sub-Saharan African, localities that have yielded diagnostic fossils of EHs: include: Elandsfontein, Florisbad, and Cave of Hearths in South Africa; Kabwe in Zambia; Ndutu, Eyasi, and Ngaloba in Tanzania; Eliye Springs in Kenya; Omo-Kibishi and Bodo in Ethiopia; and Singa in Sudan (Godinho and O'Higgins, 2018; Drennan, 1937; Day and Magori, 1980). The individuals from these sites are not anatomically modern, but they all share closer morphological resemblances to modern Homo sapiens sapiens than Homo ergaster though not without dissenting views (Mehlman, 1989; Bauer, 1984a, 1984b; Rightmire, 2009, 1984, 1983; Howell, 1984; Clark, 1976). A more complete Middle Pleistocene skull and more relevant to the present study is the Ngaloba skull from the Ngaloba beds. Despite its robust appearance, the individual displays features that are derived compared with the anatomy of Bodo or Broken Hill. A cranium similar to LH 18 is known from Ileret Kenya KNM-ER 3884 dated to 27 ka (Rightmire, 2009). Other comparable hominins include Omo 1 and Omo 2 from the Omo Valley in Ethiopia associated with an MSA lithic assemblage of a Levallois technology with core and blades and ovate handaxes dated to 195, 00о BP (Rightmire, 2009). These archaic Homo sapiens are assigned an antiquity which is at least early upper Pleistocene and associated with Acheulean, Sangoan or broadly MSA artefacts (Klindienst, 1967). While the fossil and gene records are important, it is however through archaeology that we gain glimpses into the cognitive behavioral and cultural evolution of our societies. The sub-Saharan MSA is considered the place and time where humans evolved into anatomically, genetically, and behaviourally modern humans. As such, the MSA has lately attracted a lot of studies.

The MSA in Tanzania includes a few localised industries or technocomplexes that are based on typology and technology, e.g., the ubiquitous occurrence of blades and blade cores, the employment of the Levallois technology, the sophistication of point technology, and the presence of geometric backed artefacts in some MSA assemblages. Typical MSA is represented by the Sanzako and Kisele industries overlain by LSA and subsequently Pastoral Neolithic (PN) and Iron Age (IA) industries in Lake Eyasi basin. As way back as the mid-193os 
hominid remains were discovered in association with MSA by Koh-Larsen (Recks and Kohl Larsen, 1936) on the Eyasi Lake Shore in 1935 and 1936 and attributed to the subspecies Homo sapiens rhodesiensis (Rightimire, 1975; Wells, 1957).

The most complete early $H$. sapiens cranium was found at a place along the modern Lakeshore and designated Eyasi 1. The Eyasi beds hominins include archaic H. sapiens remains (Brauer, 1984) found in association with several extinct mammalian genera; Theropithecus, Pelerovis, Hipparion, a giraffid, a large carnivore, hippopotamus, and antelope (Mehlman, 1989). The Njarasa industry from these deposits has a combination of MSA technological features and Acheulean tool types (e.g., bifaces or core axes) that is usually called Sangoan (Mehlman, 1989). In the Serengeti, the MSA has been described from Loiyalangalani (Hc-JD-1) where the artefacts include scrapers, borers, bifaces, discs, and Levallois cores produced from quartzite and obsidian (Bower, 1977) At Kisese II, a local MSA variant exhibits features such as possession of tools which are generally smaller than those of Sanzako. Most frequent are retouched points, bifacially modified pieces, and a variety of unstandardized scrapers including a few small convex and end-nosed forms. Among the rarities are blades, dubious backed pieces, and burins (Mehlman, 1989). On the same level are the industries on the eastern side of Lake Natron which display MSA features such as Levallois technology, points, blade cores, and a high proportion of flakes (Masao, 2015).

\section{Study Area}

Our survey focused on an area located on the northern bank of the Garussi River valley and gently undulating hillocks exposing extensive outcrops of lower Ngaloba beds. The Ngaloba beds are the latest in series of the 7-layered Pleistocene sedimentary sequence beginning with the Laetoli beds at the base, and followed by the Upper Laetoli, Ndolanya, Naibadad, Olpiro, and finally the Ngaloba beds (Figure 2.1). The Laetoli beds are widely distributed across the Eyasi plateau on the northern side of Lake Eyasi and onto Laetoli covering an area of more than $1000 \mathrm{~km}^{2}$ (Harrison and Kwekason, 2011). The extinct volcanic centers of Lemagrut, Satiman, Oldeani, and Ngorongoro located to the east, represent the potential sources of tephra which forms part of the deposits in the area. The Middle Pleistocene Upper Ngaloba beds as already remarked are known to have yielded MSA tools in association with faunal remains including a relatively complete cranium of EHS, LH 18 (Magori and Day, 1983; Day et al., 1980) (Figure 2.2). 


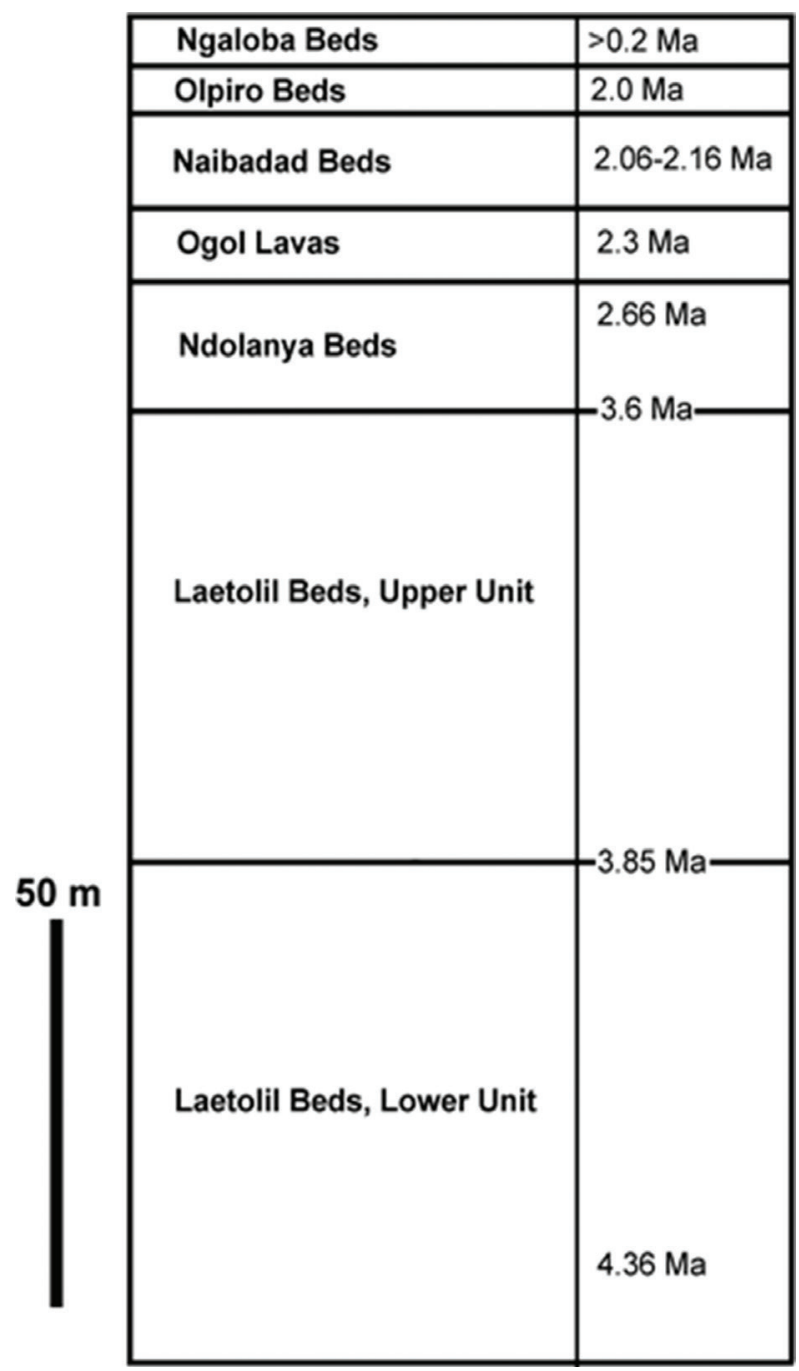

FIGURE 2.1

Simplified stratigraphy of Laetoli after Harrison 2011

The upper Ngaloba Beds deposits are known to contain assemblages that are technologically and chronologically considered to be mostly MSA while the Lower unit of the Ngaloba beds as at Locality 23, contains numerous fossil vertebrates and Acheulean artefacts. Since the MSA assemblages have not been comprehensively studied, this report should be seen as adding to the body of knowledge about the MSA in the area. Fieldwork started after obtaining the necessary permits to conduct fieldwork in the Greater Laetoli Area within the Ngorongoro Conservation Area Authority (NCAA). The fieldwork was dominated by a surface survey from which the assemblages reported here were recovered. 


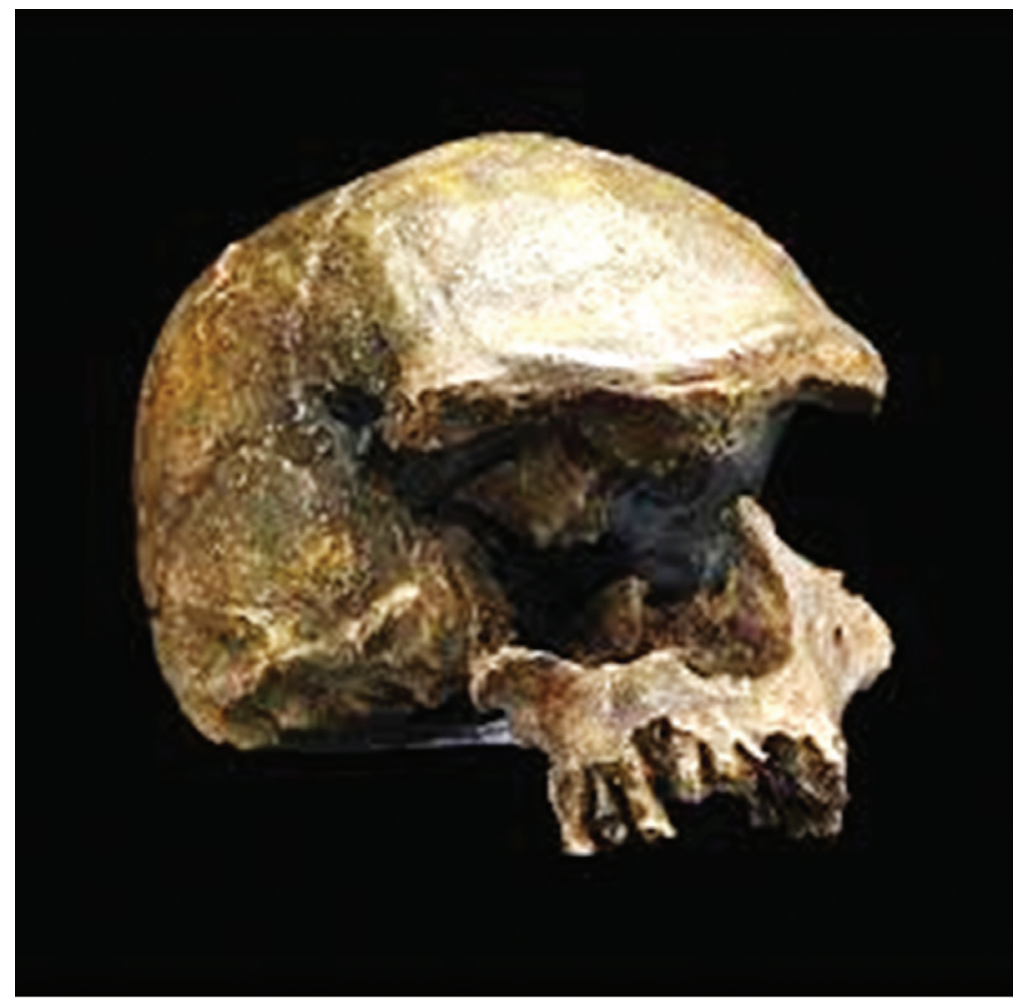

FIGURE 2.2 Early homo sapiens (LH 18) from Laetoli after Day and Magori $(1980,1983)$

The fieldwork was concentrated in the Greater Laetoli area, particularly focusing on the deposits exposed on either side of the Garussi River lying between the main road to Kakesio and Loc 1oW (Figure 2.3). These exposures are thought to consist of the upper unit of the Ngaloba beds which as remarked earlier, have been associated with MSA and LSA assemblages (Harrison and Kweka, 2011). Though there are many such exposed areas, the fieldwork team was able to survey and sample only four of the exposures, and the waypoint of the exposers for the later follow-up. Being devoid of vegetation cover, the exposures can be seen from a distance as extensive patches of brown sediments flanking the Garussi River flood plain. At or close to Locality 1oW, the exposures have taken the form of deeply incised furrows leaving cliffs and pillars reminiscent of the Isimila Korongo residual pillars in southern Tanzania. The areas are littered with many artefacts. Several exposures were sampled for artefacts. Altogether a total of 710 artefacts were retrieved. 


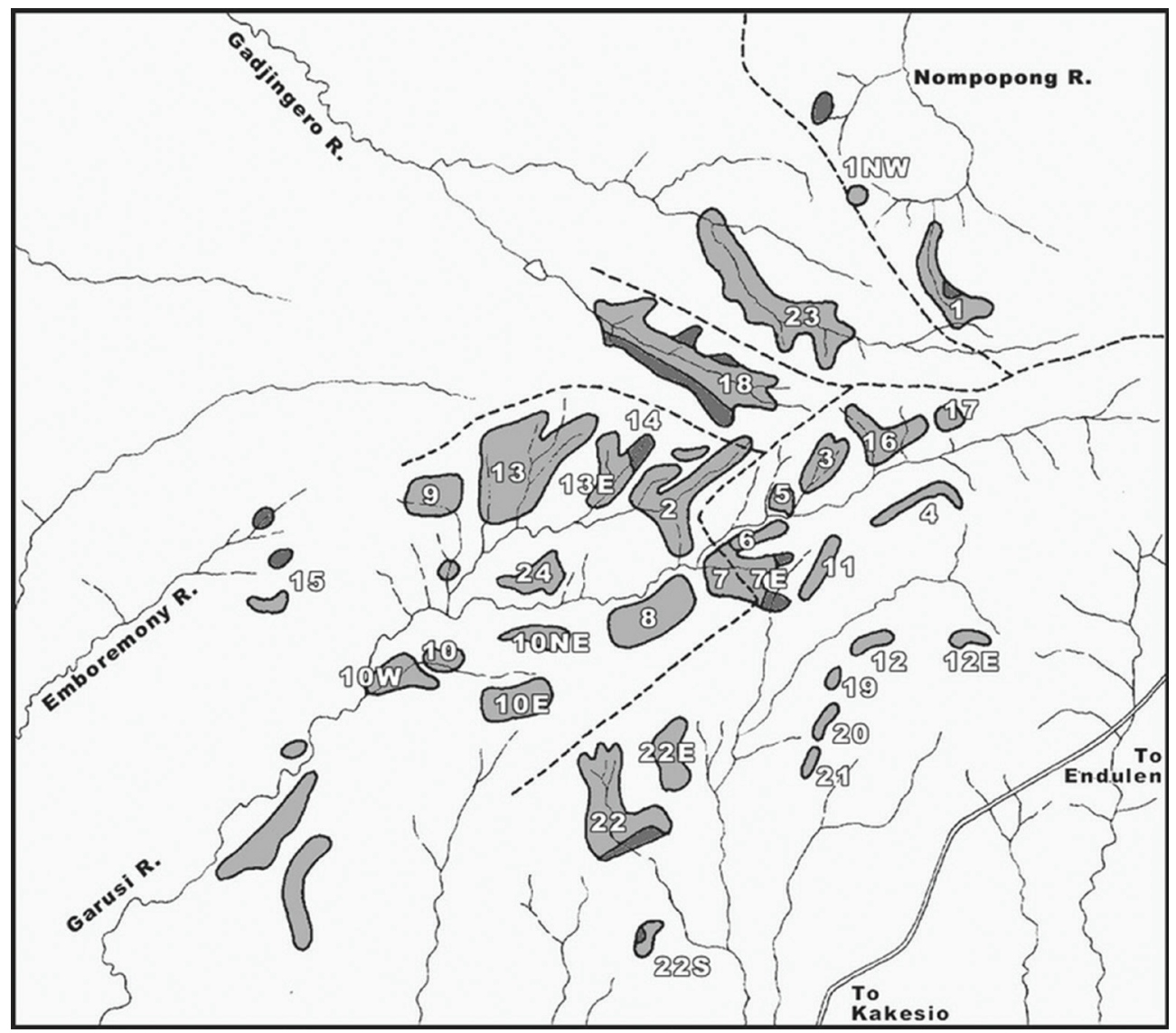

FIGURE 2.3 Map of Laetoli showing localities and area of fieldwork after Harrison et al 2011

Both systematic and unsystematic surveys were used to recover the data described in this article. The former took two forms, transect and total collection in prescribed areas. As for the first one, a 7om long transect was laid in the $\mathrm{N}-\mathrm{S}$ direction in one of the exposures (Exp A), and all artefacts $5 \mathrm{~m}$ on either side were collected and bagged. Another transect was laid perpendicular to the first transect and as in the previous one, the artefacts and bones were collected. Two more transects, both 5 om long were established one $10 \mathrm{~m}$ from the edge of the exposure and the other $20 \mathrm{~m}$ from the edge of the flood plain and artefacts retrieved. 
Total Collection from circles: Another systematic sampling strategy adopted was to inscribe circles and collect all artefacts and bones. Two such circles of $10 \mathrm{~m}$ and $5 \mathrm{~m}$ radii were inscribed at different places in the exposure and artefacts collected. The table summarises the number of artefacts thus collected.

Test pits. Four test pits of varying sizes were dug in order to assess the vertical distribution of the artefacts, to see if the surface material is a mirror image of the subsurface material. Unfortunately, the test pits did not reveal much material. Based on the few artefacts that were found, one can say the surface and stratified material belong to the same component. This point will be taken up later when the analysis has been completed.

In addition to the above strategies, unsystematic pedestrian survey was employed to cover as much area of the three exposures as possible, two on the western and one on the eastern side of the Garussi River. The team members having been instructed on what to look for, i.e., artefacts and identifiable fossilized bone, walked over the terrain. Many artefacts and bones were collected in the process as reported in the tables below (Tables 2.1 and 2.2).

\section{$5 \quad$ Results}

The fieldwork recovered a total of 710 lithic items and 78 faunal remains (Table 2.1 and 2.2). The majority of these artefacts were from the surface collection and only a few were recovered from test pits excavation. Most of the lithic artifacts are made from the Ogol lava which is locally obtained in the area. Artefacts made from chert quartzite, obsidian, and Iron-banded rocks are present in the assemblage but only in negligible percentages.

The lithic assemblage is made up of a variety of unifacially and bifacially trimmed forms which are traditionally associated with MSA, as shown in the Table 2.1. Utilized flakes, flakes, and blades (26.5 and $15.4 \%$ ) outnumber the rest of the tool category on the assemblage. Scrapers contribute a significant amount of the assemblage while cores, cleavers, choppers, and burin are less common (Figure 2.4 and 2.5). A sizeable component of the assemblage is made up of tools types that would be scored as LSA on account of their small sizes, i.e. microlithic. These include geometrics, backed pieces, scrapers, and unmodified flakes.

A total of 78 faunal remains representing different genera were recovered from the surface. Bovids are most common in the assemblage (Table 2.2). Other genera are also represented but in a small percentage. Most of the bones 
TABLE 2.1 Summary of artefacts recovered from the survey

Artifact type Transect A Transect B Circle A Unsystematic Testpit Total Percentage \&B Survey

(\%)

\begin{tabular}{|c|c|c|c|c|c|c|c|}
\hline Flakes/Blade & 55 & 41 & 22 & 67 & 3 & 188 & 26.5 \\
\hline Utilized flakes & $3^{2}$ & 29 & 16 & $3^{\circ}$ & 2 & 109 & $15 \cdot 4$ \\
\hline Backed pieces & 35 & 12 & 11 & 33 & 1 & 92 & 13 \\
\hline Scrapers & 28 & 10 & 8 & 21 & 2 & 69 & $9 \cdot 7$ \\
\hline $\begin{array}{l}\text { Unifacial } \\
\text { point }\end{array}$ & 14 & 5 & 5 & 19 & o & 43 & 6.1 \\
\hline Bifacial point & 9 & 7 & 3 & 7 & o & 26 & $3 \cdot 7$ \\
\hline Burin & 5 & 2 & 2 & 5 & o & 14 & 2.0 \\
\hline $\begin{array}{l}\text { Biface } \\
\text { dimunitive }\end{array}$ & 5 & 6 & 1 & 7 & O & 18 & 2.5 \\
\hline Biface large & 2 & 3 & 1 & 3 & o & 9 & 1.3 \\
\hline Cleaver & 1 & o & O & 2 & 1 & 4 & o.6 \\
\hline Core axe & 2 & 1 & 3 & 3 & 1 & 11 & 1.5 \\
\hline Chopper & 2 & 2 & 2 & 3 & $\mathrm{O}$ & 9 & 1.3 \\
\hline $\begin{array}{l}\text { Core } \\
\text { peripheral }\end{array}$ & 11 & 12 & 8 & 13 & 3 & 47 & 6.6 \\
\hline Core bipolar & 5 & 6 & 4 & 3 & 2 & 20 & 2.8 \\
\hline Core irregular & 16 & I3 & 8 & 11 & 3 & 51 & 7.2 \\
\hline Total & 222 & 149 & 94 & 227 & 18 & 710 & \\
\hline
\end{tabular}

display medium weathering stage 1 (Behrensmeyer, 1978). Despite the small sample, it nevertheless represents the expected Middle Pleistocene fauna which is as shown from the nearby Lake Eyasi basin and southern Serengeti is mostly modern with the exception of five extinct taxa: Theropithecus oswaldi, Pelerovis sp, Hipparion sp., Sivatherium sp., and Hippopotamus (Dominguez et al., 2007). As of today, bovids followed by equids are the most frequent genera. Cursory examination for surface modification revealed that the majority of the bovid and equid specimens displayed bone surface modification in form of cut marks and percussion though some of the marks could have been concealed by the weathering. The bones displayed no evidence of carnivore modification such as tooth marks. 
TABLE 2.2 Summary of fossil bones recovered according to genera

\begin{tabular}{lcc}
\hline Genus & Number & Percentage (\%) \\
\hline Bovid & 40 & 51.9 \\
Equid & 14 & 17.9 \\
Rodents & 5 & 6.4 \\
Ostrich & 4 & 5.1 \\
Suid & 2 & 2.56 \\
Canid & 2 & 2.56 \\
Giraffe & 1 & 1.28 \\
Hippo & 1 & 1.28 \\
Non-Identified & 9 & 11.5 \\
\hline
\end{tabular}

\section{$6 \quad$ Discussion and Conclusions}

Unlike the nearby Lake Eyasi basin sites which are sealed and hence yield undisturbed association of lithic and faunal remains, the Ngaloba remains lack this context. Most artefacts and ecofacts reported here are surface collection. These were found littering on the surface following erosion of the upper Ngaloba beds. Suffice it to point out that comparable assemblages have been recovered from Ngaloba stratified contexts and described as MSA (Mabulla, 2015). On the other hand, the surface finds may bespeak a persistent place. As Camilli and Ebert (1992) point out, the argument that post-deposition processes and disturbance render surface distribution of artefacts of little use for analysis has also been countered with the assertion that almost all assemblages presently buried or on the surface have been subjected to these disarranging processes because all assemblages are originally surface assemblages. Along this vein, the spatial integrity of sealed deposits has recently been likened to no more than that of surface deposits (Ebert, 1992).

Our short fieldwork did not investigate how far the contact with the lower Ngaloba beds would be from the exposures. As such, we did not establish the relationship with any underlying deposits such as Acheulean or any pre MSA assemblages. One thing seems certain though, the underlying deposits, seem, on account of what the test pits revealed, to be almost devoid of artefacts. There are several possible explanations for this. First, it is possible that the Kakesio and the greater Laetoli area may contain a very thin layer of MSA assemblage that has been exposed by erosion. This would imply that hominins 


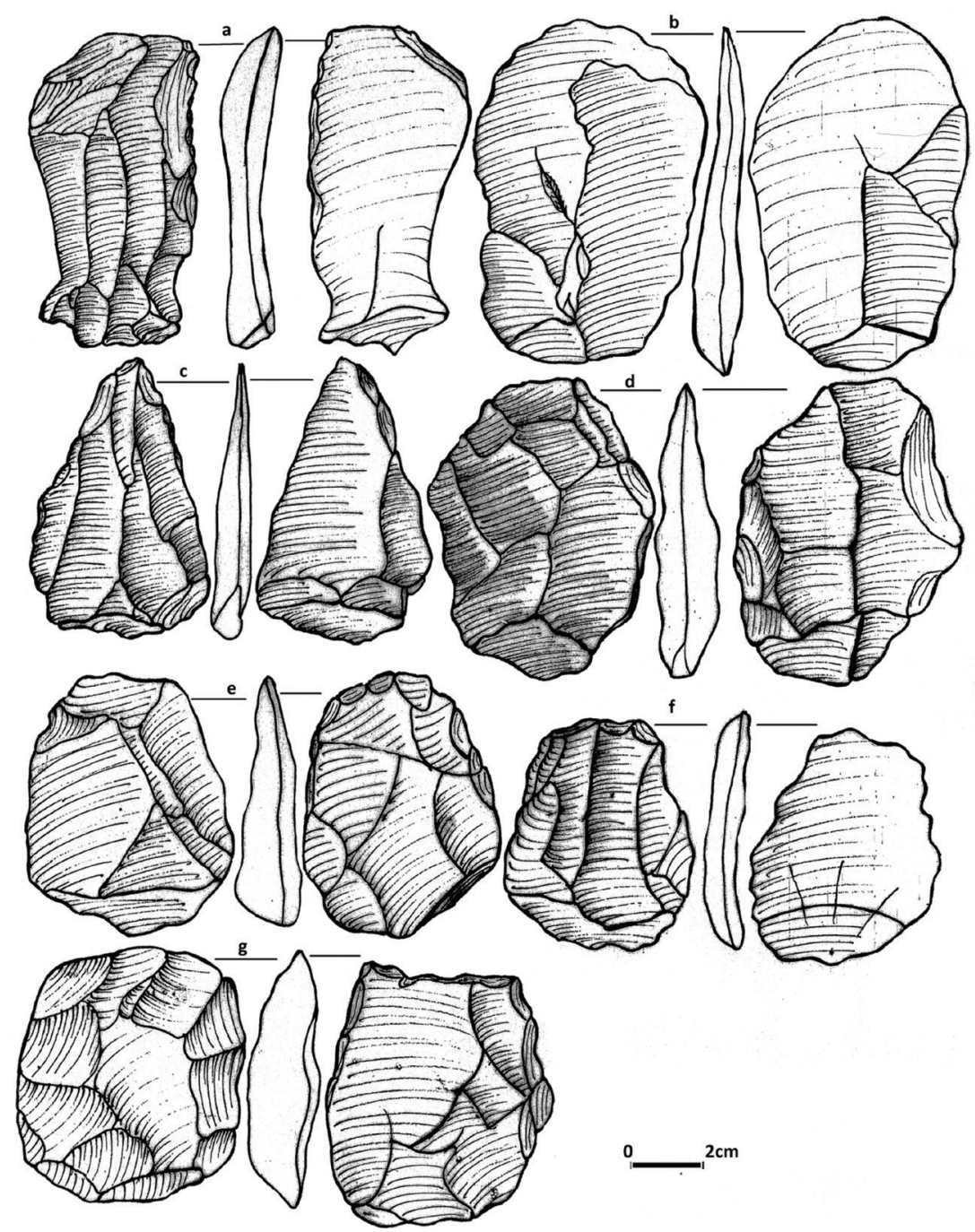

FIGURE 2.4 Some of the artefacts retrieved from the Ngaloba Beds: (A) Levallois Flake, (B-D) Diminutive Bifaces (C) Bifacial Point (E-F) Scarpers (G) Diminutive Cleaver Scraper

occupied this area for during a very short period. Second, we cannot rule out the possibility that our test pits were dug on a non-stratified spot. The nearest well investigated locality to the study area is the Lake Eyasi basin including Mumba Hohle where following Kohl-Larsen studies, Mehlman has conducted a detailed investigation of the Quaternary archaeology revealing a long sequence documenting the Acheulean-MSA and MSA-LSA transitions up to Pastoral Neolithic (PN) industries (Kohl-Larsen, 1943; Mehlman, 1989). In addition to 

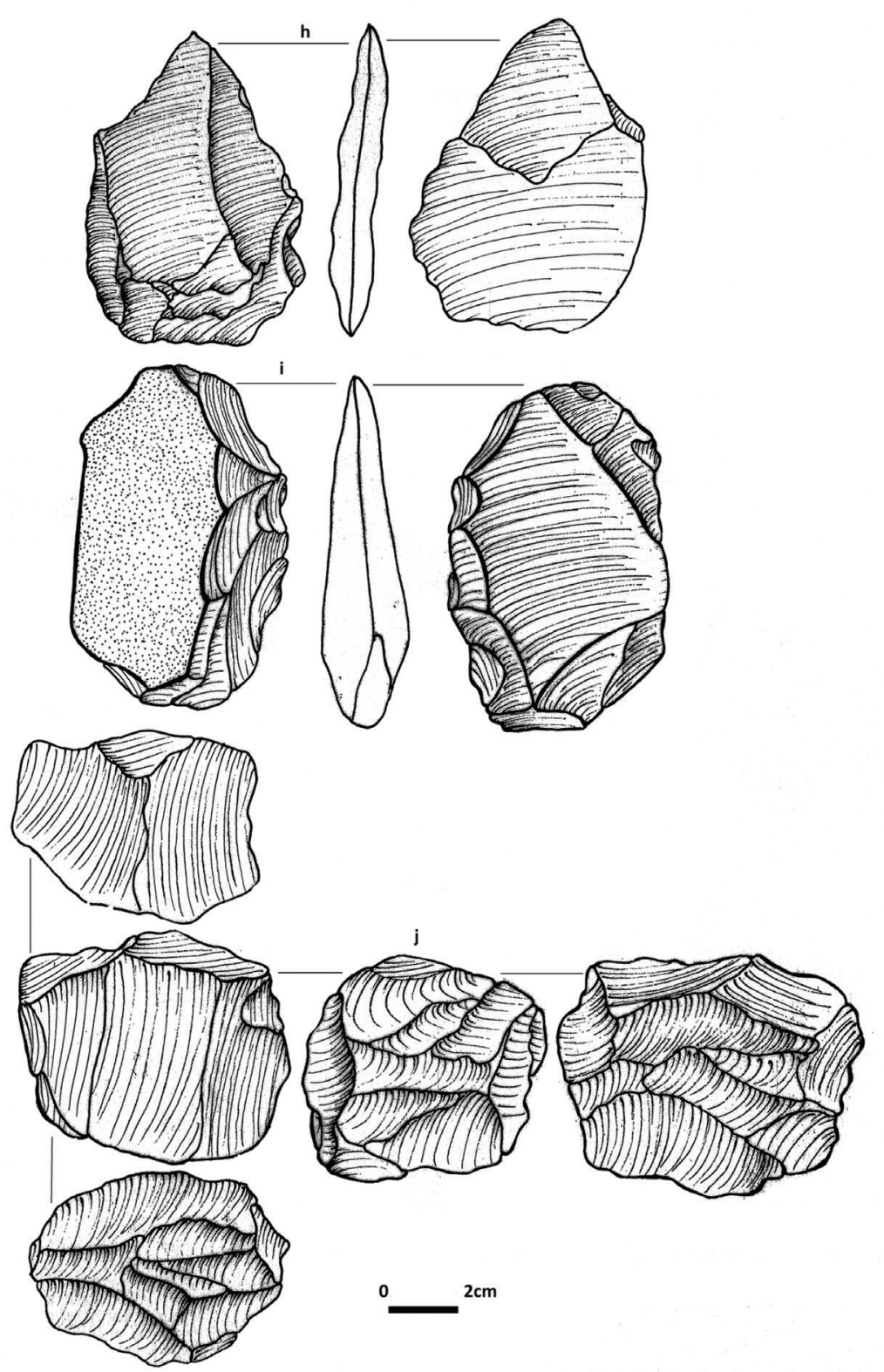

FIGURE 2.5 MSA artefacts retrieved from the Ngaloba Beds: (H) Point (I) Scraper (J) Core

MSA, LSA, and PN sequence, the Lake Eyasi basin has revealed important early Homo specimens associated with an early MSA industry described as the Njarassa. These include three individuals discovered by Kohl-Larsen's expedition (Reck and Kohl-Larsen, 1936) and another discovery of a skull fragment in 1993 
(Brauer and Mabulla, 1996). The Eyasi hominin remains have now been dated to at least $100 \mathrm{ka}$ and most likely older than $130 \mathrm{ka}$. (Mehlman, 1984) and hence contemporary with the Ngaloba hominin.

The majority of the lithic artefacts are manufactured from basalt obtained from nearby exposures of basaltic lava, the Ogol lava. This observation is interesting because as Mabulla 2015 and Adelsberger et al., 2002 and 2011 observed, the raw material from which the Middle Pleistocene MSA artefacts from Upper Ngaloba beds include local and non-local materials. The local materials would be dominated by the Ogol lava while non-local material consists of other forms of lava such as trachyandesite, and phonolite as well as nonvolcanic material such as quartzite, gneiss, chert, etc. For reasons presently not clear, the hominins in the Greater Laetoli area seem to have been satisfied with the use of the Ogol lava which as was seen from the surface easily obtained. The artefacts have a mixture of light duty implements, sometimes becoming microscopic, in addition to large duty forms. While the former component suggests LSA affinity, the latter would suggest MSA belongingness. This mixture has led Mabulla (2015), Tyron et al. (2014) to refer to the industry as Early Middle Stone Age (EMSA) or Ngaloba industry. However, the recent fieldwork has observed very few light-duty or microlithic implements. This result can be interpreted as spatial variability within the assemblages associated with the upper Ngalobal beds, an indication of site use variability or intersite variability.

The above observation is supported by the fact that the artifact assemblage discussed here unlike the ones that have been reported by Mabulla 2015 are dominated by heavy duty tools. Alternatively, it must be underscored that since the assemblages discussed here are as remarked earlier surface, natural post depositional factors may have washed away the less bulky artefacts leaving the heavy-duty artefacts behind. It is tempting to surmise if the Ngaloba industry described here could be a variant of the Njarassa industry described from the nearby Lake Eyasi basin by Mehlman (1989). Some of the bifaces such as the ovate handaxes and core axes could pass as belonging to Sangoan and hence Mabullla's description of the Ngaloba MSA as early MSA (Mabulla, 2015). Alternatively, the industry is possibly a highland expression of the Njarassa, but this needs a larger sample. Another variant of the MSA not too far away from Ngaloba has been recognised at Nasera in southern Serengeti where the industry displays a mixture of MSA and LSA technocomplex. Most of the artefacts are made from quartzite, though there is a low frequency of obsidian and chert described by Mehlman (1989) as the Naseran industry. Employment of comparable raw materials has also been observed in the MSA/LSA industries in the eastern Lake Natron (Masao, 2015; Mehlmam, 1989; Isaac, 1966). The 
lowest MSA/LSA Naseran industry levels seem to have dates that are appreciably younger than those of Kisele and Sanzako being 55,96o $\pm 2,675-18,475$ \pm 86 o. Moreover, the Upper Ngaloba trachytic tuff has been correlated to the lower Ndutu marker tuff at Olduvai (Day et al., 1980). A uranium series date of ca 129,000 $\pm 4,000$ B.P. associated with early H. sapiens ( LH 18) immediately postdates the trachytic tuff at Laetoli (Hay, 1987).

As remarked earlier, few bones were collected. We are not sure that they are from MSA horizon despite finding them with the MSA assemblages. Although fossil remains from the Laetoli beds are dispersed and fragmented (e.g., Leakey et al., 1979: 164), our faunal sample exhibit a medium weathering stage as they were relatively from a recent ongoing erosion (Behrensmeyer, 1978). This has contributed to the preservation of surface modification in form of cut marks and percussion marks. These modifications have broader implication of MSA tools uses and feeding behaviour. Documentation of surface modification analysed together with the artefacts shed light on food procurement strategies of the Ngaloba LH 18 folks, but one would require a larger sample in order to make more meaningful statements about EHs' food procurement hypotheses. Archaeological remains such as bone tools, points projectile and cut marked bones suggest that humans started active hunting during the MSA period (Badenhorst et al., 2016; Stiner et al., 2009; Wadley et al., 2009; Clark and Plug, 2008; Brooks, 2006; Lombard, 2012; McCall, 2015). Some of the artefacts e.g., the points and projectiles as reported by Mabulla (2015) could have been used for hunting, it is not unimaginable, that the faunal remains and modification thereof are associated with the assemblage and that LH 18 was capable of hunting. Hunting during the MSA is well studied in southern Africa archaeological sites (e.g., Faith, 2013; Dusseldorp, 2012; Brooks, 2006; Marean, 2005). However, this topic is poorly investigated in eastern Africa due to the lack of zooarchaeological studies on fauna assemblage recovered from MSA (Prendergast et al., 2007). As a result, this limits our knowledge and understanding about butchering and foraging behaviour during MSA period (Prendergast et al., 2007). Therefore, we recommend that future study should focus on locating insitu faunal and lithic remains. Second, a systematic investigation of faunal remains should be undertaken to investigate carcass acquisition and butchering behaviour during the MSA period. Only then we can properly use the assemblage to address questions of LH 18 and related hominins behaviour and cognition.

\section{Acknowledgements}

Our field trip was completed with a generous support from Palaeontological Scientific Trust (РAST). We thank the Antiquities Department and the NCAA 
for issuing necessary permits to conduct our filed work in the Greater Laetoli Area. We acknowledge the contributions of the trained hominin hunters from Olduvai and local community during our data collection.

\section{References}

Adelsberger, K.A., Wirth, K.R., and Mabulla, A.Z.P. 2002. Provenance of Middle Stone age Tools of the Laetoli archaeological site, Tanzania. Geological Society of America (GSA), Abstract with Programs 34: 110.

Adelsberger, K.A., Wirth, K.R., and Mabulla, A.Z.P. 2011. Geochemical and mineralogical characterisation of Middle Stone Age tools of Laetoli, Tanzania and comparisons with possible source materials. In: Harrison, T. (eds) Paleontology and geology of Laetoli, Tanzania: Human evolution in context: Geology, geochronology, paleoecology and paleoenvironment. Springer: Dordrecht, Netherlands, pp. 143-165.

Badenhorst, S., Van Niekerk, K., and Henshilwood, C. 2016. Large mammal remains from the 1ooka Middle Stone Age layers of Blombos Cave, South Africa. The South African Archaeological Bulletin 71(203): 46-52.

Behrensmeyer, A.K. 1978. Taphonomic and ecologic information from bone weathering. Paleobiology 4(2): 150-162.

Bower, J.R.F. 1977. Preliminary report of a study of prehistoric cultures of the Serengeti National Park. Nyame Akuma 11: 20-27.

Bräuer, G. 1984. A craniological approach to the origin of anatomically modern Homo sapiens in Africa and implications for the appearance of modern Europeans. The origins of modern humans: a world survey of the fossil evidence 327-410.

Bräuer, G. 1989. The evolution of modern humans: A comparison of the African and non-African evidence. In: Mellars, P., and Stringer, C.B. (eds) The human revolution. Edinburgh University Press: Edinburgh Scotland, pp. 123-154.

Brauer, G., and Mabulla, A.Z.P. 1996. A new fossil hominid from Lake Eyasi, Tanzania. Anthropologie 34: 47-53.

Brooks, A.S., Nevell, L., Yellen, J.E., and Hartman, G. (2006). Projectile Technologies of the African MSA. In: Hovers, E., and Kuhn, S.L. (eds) Transitions Before the Transition: Evolution and Stability in the Middle Paleolithic and Middle Stone Age, Interdisciplinary Contributions to Archaeology. Springer: Boston, USA, pp. 233-255.

Camilli, E.L., and Ebert, J.I. 1992. Artifact reuse and recycling in continuous surface distributions and implications for interpreting land use patterns. In: Space, time, and archaeological landscapes. Springer: Boston, MA, USA, pp. 113-136.

Clark, J.L., and Plug, I. 2008. Animal exploitation strategies during the south African middle stone Age: Howiesons Poort and post-Howiesons Poort fauna from Sibudu cave. Journal of Human Evolution 54(6): 886-898. 
Day, M. H., Leakey, M. D., and Magori, C. 1980. A new hominid fossil skull (LH 18) from the Ngaloba Beds, Laetoli, northern Tanzania. Nature 284(5751):55-56.

Drake, R., and Curtis, G. 1987. K-Ar geochronology of the Laetoli fossil localities. In: Leakey, M.D., and Harris, J.M. (eds) Laetoli: A Pliocene site in northern Tanzania. Clarendon Press: Oxford, UK, pp. 48-51.

Domínguez-Rodrigo, M., Díez-Martín, F., Mabulla, A.Z.P., Luque, L., Alcalá, L., Tarrino, A., López-Sáez, J.A., Barba, R., and Bushozi, P. 2007. The archaeology of the Middle Pleistocene deposits of Lake Eyasi, Tanzania. Journal of African Archaeology 5(1): $47-78$.

Dusseldorp, G.L. 2010. Prey choice during the South African Middle Stone Age: avoiding dangerous prey or maximising returns? African Archaeological Review 27(2): 107-133.

d'Errico, F., and Banks, W.E. 2013. Identifying mechanisms behind middle paleolithic and middle stone age cultural trajectories. Current Anthropology 54(S8): $\mathrm{S}_{371}-\mathrm{S}_{3} 87$.

d'Errico, F., Vanhaeren, M., Barton, N., Bouzouggar, A., Mienis, H., Richter, D., Hublin, J. J., McPherron, S.P., and Lozouet, P. 20og. Additional evidence on the use of personal ornaments in the Middle Paleolithic of North Africa. Proceedings of the National Academy of Sciences of the USA 106(38): 16051-16056.

Ebert, J.I. 1992. Distributional archaeology. University of Utah Press: Utah, USA.

Faith, J.T. 2013. Taphonomic and paleoecological change in the large mammal sequence from Boomplaas Cave, western Cape, South Africa. Journal of Human Evolution $65(6): 715^{-73}$.

Godinho, R.M., and O'Higgins, P. 2018. The biomechanical significance of the frontal sinus in Kabwe 1 (Homo heidelbergensis). Journal of Human Evolution 114:141-153.

Hay, R.L. 1987. Geology of the Laetolil area. In: Leakey, M.D., and Harris, J.M. (eds) Laetoli: A Pliocene site in northern Tanzania. Clarendon Press: Oxford, UK, pp. 23-61. Harris, J.M. 1985. Age and paleoecology of the upper Laetolil beds, Laetoli, Tanzania. Ancestors: The Hard Evidence. Alan R. Liss: New York, USA, pp. 76-81.

Harrison, T. 2015. Paleontology and Geology of Laetoli: Human Evolution in Context: Vol 2. Fossil Hominins and the Associated Fauna. Springer: New York, USA.

Harrison, T. 2011. Hominines from the upper Laetoli and Upper Ndolonya Beds, Laetoli. In: T. Harrison (eds), paleontology and geology of Laetoli: human evolution in context Vol. 2: fossil hominids and the associated fauna. Springer: Dordrecht, Netherlands, pp. 141-188.

Harrison, T., and Kwekason, A. 2011. Paleontological localities on the Eyasi Plateau, including Laetoli. In: Paleontology and geology of Laetoli: Human evolution in context. Springer: Dordrecht, Netherlands 17-45.

Harrison, T. 1997. Neogene paleontology of the Manonga Valley, Tanzania: a window into the evolutionary history of east Africa. Topics in Geobiology. Plenum Press: New York, USA. 
Herries, A.I. 2011. A chronological perspective on the Acheulian and its transition to the Middle Stone Age in southern Africa: the question of the Fauresmith. International Journal of Evolutionary Biology 1-25.

Henshilwood, C.S., and Lombard, M. 2013. Becoming human archaeology of the sub-Saharan Middle Stone Age. In: Renfrew, C., and Bahn, P. (eds). The Cambridge World Prehistory Vol.r. Cambridge, University Press: Cambridge, United Kingdom, pp. 106-130.

Howell, F.C. 1984: Introduction. In: Smith, F.S., and Spencer, F. (eds). The origins of modern humans: A world survey of the fossil evidence. New York Alan R Liss: New York, USA, pp. xiii-xxii.

Isaac, G.L. 1966. The Middle and Later Stone Ages. In: Posnansky., M. (ed). Prelude to East African History. Oxford University Press: London, United Kingdom, pp. 43-50.

Kohl-Larsen, L. 1943 Auf den spuren der vor menchen 2 vols. Stuttgart Strecker und Schroder, Verlag: Berlin, Germany.

Leakey, M.D. 1987a. Introduction. In: M.D Leakey and J.M Harris (eds), Laetoli: A Pliocene Site in Northern Tanzania. Clarendon Press: Oxford, UK, pp. 1-22.

Leakey, M.D. 1987b. The Laetoli hominid remains In Leakey, M.D., and Harris, J.M. (eds) Laetoli: A Pliocene site in northern Tanzania. Clarendon: Oxford, UK, pp. 108-117.

Leakey, M.D., and Hay, R.L. 1979. Pliocene footprints in the Laetoli Beds at Laetoli, northern Tanzania. Nature 278(5702): 317-323.

Leakey, M.D., Hay, R.L., Curtis, G.H., Drake, R.E., Jackes, M.K., and White, T.D. 1978. Fossil hominids from the Laetolil beds, Tanzania. Geological Society, London, Special Publications 6(1): 157-170.

Leakey, M.D. 1984. The Laetoli years. In: Leakey, M.D. (ed), Disclosing the Past. Doubleday: New York, USA, pp. 168-184.

Leakey, M.D. 1978. Pliocene footprints at Laetoli, northern Tanzania. Antiquity 52(205):133. Lombard, M. 2012. Thinking through the Middle Stone Age of sub-Saharan Africa. Quaternary International 270: 140-155.

Mabulla, A.Z.P. 2015. Middle Pleistocene Lithic Industry and Hominin Behavior at Laetoli. Africana Studia 24(1): 13-32.

Magori, C.C., and Day, M.H. 1983. An Early Homo sapiens Skull from the Ngaloba Beds, Laetoli, Northern Tanzania in the Proceedings of the 3rd European Congress of Anthropology, 25-3o Sept. 1982 at Petralona Chalkidiki. Anthropos. Etesio Organo tes Anthropologikes Etaireias Ellados Athinai 10: 143-183.

Marean, C.W., and Assefa, Z. 2005. The Middle and Upper Pleistocene African record for the biological and behavioral origins of modern humans. African Archaeology 93-129.

Masao, F.T., Ichumbaki, E.B., Cherin, M., Barili, A., Boschian, G., Iurino, D.A., Menconero, S., Moggi-Cecchi, J., and Manzi, G. 2016. New footprints from Laetoli (Tanzania) provide evidence for marked body size variation in early hominins. Elife 5: e19568. 
Masao, F.T. 2015. Characterising Archaeological Assemblages from Eastern Lake Natron, Tanzania: Results of Fieldwork Conducted in the Area. African Archaeological Review 32(1): 137-162.

McBrearty, S. 1988. The Sangoan-Lupemban and Middle Stone Age sequence at the Muguruk site, western Kenya. World Archaeology 19(3): 388-420.

McCall, G.S. 2015. Before modern humans: new perspectives on the African Stone Age. Left Coast Press: California, USA.

Mehlman, M.J. 1989. Later Quaternary Archaeological Sequences in Northern Tanzania. Unpublished Ph.D. Thesis. University of Illinois: Illinois, USA.

Mehlman, M.J. 1984. Archaic Homo sapiens at Lake Eyasi, Tanzania: recent misrepresentations. Journal of Human Evolution 13(6): 487-501.

Ndessokia, P.N.S. 199o. The Mammalian fauna and Archaeology of the Ndolanya and Olpiro Beds, Laetoli, Tanzania. Ph.D. Thesis. University of California: California, USA. Prendergast, M.E. 2007. New excavations at Mumba Rock-shelter, Tanzania. Journal of African Archaeology 5(2): 217-243.

Reck, H., and Kohl-Larsen, L. 1936. Erster Uberblick uber die jungdiluvialen Tier-und Menschenfunde von Dr. Kohl-Larsen um Norddostlichen Teil des Njarassa Grabens (Ostafrka) Geologische Rundschau 27: 401-441.

Rightmire, G.P. 2009. Middle and later Pleistocene hominins in Africa and Southwest Asia. Proceedings of the National Academy of Sciences of the USA 106(38): 16046-16o5o.

Rightmire, G.P. 1983: The Lake Ndutu Cranium and early Homo sapiens in Africa. American Journal of Physical Anthropology 61: 245-254.

Rightmire, G.P. 1975. Problems in the Study of Later Pleistocene Man in Africa 1. American Anthropologist 77(1): 28-52.

Rightmire, G.P. 1984. Homo sapiens in sub-Saharan Africa. In: Smith, H., and Spencer, F. (sds), The origins of modern humans. Alan Liss: New York, USA pp. 295-325.

Stiner, M.C., Barkai, R., and Gopher, A. 20og. Cooperative hunting and meat sharing 400-200 ka at Qesem Cave, Israel. Proceedings National Academy of Sciences 106: $13207-13212$.

Willoughby, P.R. 2006. The evolution of modern humans in Africa: A comprehensive guide. Rowman Altamira.

White, T.D. 1980. Additional fossil hominids from Laetoli, Tanzania: 1976-1979 specimens. American Journal of Physical Anthropology 53(4): 487-504. 